\title{
Microbial communities of a variety of cheeses and comparison between core and rind region of cheeses
}

\author{
Jungmin Choi, ${ }^{1}$ Sang In Lee, ${ }^{1} \oplus$ Bryna Rackerby, ${ }^{1}$ Lisbeth Goddik, ${ }^{1} \odot$ Robin Frojen, ${ }^{1} \odot$ Sang-Do Ha, ${ }^{2}$ \\ Jang H. Kim, ${ }^{3}$ (i) and Si Hong Park ${ }^{1 *}$ (D) \\ ${ }^{1}$ Department of Food Science and Technology, Oregon State University, Corvallis 97331 \\ ${ }^{2}$ Department of Food Science and Technology, Advanced Food Safety Research Group, Brain Korea 21 Plus, Chung-Ang University, \\ South Korea 06974 \\ ${ }^{3}$ School of Family and Consumer Sciences, College of Agricultural and Life Sciences, University of Idaho, Moscow 83844
}

\begin{abstract}
Understanding the microbial community of cheese is important in the dairy industry, as the microbiota contributes to the safety, quality, and physicochemical and sensory properties of cheese. In this study, the microbial compositions of different cheeses (Cheddar, provolone, and Swiss cheese) and cheese locations (core, rind, and mixed) collected from the Arbuthnot Dairy Center at Oregon State University were analyzed using 16S rRNA gene amplicon sequencing with the Illumina MiSeq platform (Illumina, San Diego, CA). A total of 225 operational taxonomic units were identified from the 4,675,187 sequencing reads generated. Streptococcus was observed to be the most abundant organism in provolone (72 to $85 \%$ ) and Swiss (60 to $67 \%$ ), whereas Lactococcus spp. were found to dominate Cheddar cheese (27 to $76 \%$ ). Species richness varied significantly by cheese. According to alpha diversity analysis, porter-soaked Cheddar cheese exhibited the highest microbial richness, whereas smoked provolone cheese showed the lowest. Rind regions of each cheese changed color through smoking and soaking for the beverage process. In addition, the microbial diversity of the rind region was higher than the core region because smoking and soaking processes directly contacted the rind region of each cheese. The microbial communities of the samples clustered by cheese, indicated that, within a given type of cheese, microbial compositions were very similar. Moreover, 34 operational taxonomic units were identified as biomarkers for different types of cheese through the linear discriminant analysis effect size method. Last, both carbohydrate and AA metabolites comprised more than $40 \%$ of the total functional annotated genes from 9 varieties of cheese samples. This study provides insight into the microbial composition
\end{abstract}

Received August 14, 2019.

Accepted January 8, 2020.

*Corresponding author: sihong.park@oregonstate.edu of different types of cheese, as well as various locations within a cheese, which is applicable to its safety and sensory quality.

Key words: cheese, microbiome, Illumina MiSeq

\section{INTRODUCTION}

Cheese is a nutrient-rich food that contains vitamins, minerals, proteins, bioactive peptides, AA, fats, and fatty acids (Walther et al., 2008). The microorganisms present in cheese not only influence the flavor profile through the production of volatile compounds (Percival and Percival 2017), but also potentially contribute to human health associated with anti-cancer and cholesterol-lowering properties (Walther et al., 2008; Broadbent et al., 2011; Potočki, 2016).

The microbiomes and metabolomes of cheeses vary and are based on the cheese type as well as environmental and processing conditions such as starter cultures, pasteurization methods, cooking temperatures, and aging conditions (Didienne et al., 2012; Montel et al., 2014; Duru et al., 2018). Bacteria primarily originate from 2 sources: the inoculated starter cultures and the indigenous milk microbiota (Montel et al., 2014; De Filippis et al., 2016). Microorganisms originating from processing environments are also transferred from production surfaces to cheese surfaces where they affect the microbial composition of rinds during aging (Bokulich and Mills, 2013). Bacteria are essential for the formation of cheese and are largely responsible for flavor development and nutritional benefits (Walther et al., 2008; Didienne et al., 2012; Montel et al., 2014). In addition, microorganisms originated from processing environments dominate both surfaces of cheese and facilities and affect the microbial composition of cheese rinds during aging (Bokulich and Mills, 2013).

The rind and core regions of a given cheese exhibit different microbial compositions. This is due in part to the differences in oxygen availability throughout the cheese. The presence of oxygen at the cheese surface 
allows for the growth of aerobic organisms that are unable to grow deeper where less oxygen can penetrate. A natural rind is developed through interactions between the surface and the environment during the aging process. Another type of rind is the washed rind, which usually has a sticky texture and strong flavor. When a cheesemaker soaks (or washes) a cheese with a brine or alcohol, the bacteria from the environment or soaking material grow on the surface of the cheese and develop the rind (Donnelly, 2014). Bacteria commonly found on cheese rinds include gram-negative bacteria, such as Advenella, Psychrobacter, and Psychroflexus, which contain various lipases, proteases, and other enzymes that enhance aging (Schmitz-Esser et al., 2018). Moisture content of cheese also affects the microbial diversity (Pintado and Malcata, 2000). Vacuum packaging affects the microbial and physical properties of the cheese rind, as moisture content and texture do not change significantly while under a vacuum. Conversely, unpackaged cheeses exhibit a substantial loss of water with a concomitant increase in rigidity.

The development of next-generation sequencing technologies has helped researchers obtain genomic information quickly at a low cost and has furthered our understanding of the microbial properties of target food matrices. High-throughput sequencing has made it possible to explore food microbiomes and to investigate the genomes of individual organisms. Next-generation sequencing can reveal how microbes respond to environmental conditions, allowing cheesemakers to better control microbial growth in their products based on predictions of how conditions will affect the growth of both beneficial and undesirable organisms (Solieri et al., 2013).

It is important to understand what conditions can cause changes in the cheese microbiome since some organisms impart beneficial sensory characteristics, whereas others may reduce quality through the production of spoilage compounds. Knowledge of food microbiomes is important with foods that are fermented or aged, as these are primarily microbe-driven processes and the microbes present will drastically affect the outcome (Mayo et al., 2014). In this study, we examined 3 different cheeses (Cheddar, provolone, and Swiss) produced plain or treated by soaking in cider, pinot noir (wine), or porter (beer), or by smoking. All the cheese samples were produced at the Arbuthnot Dairy Center at Oregon State University (Corvallis, OR). Microbial communities were analyzed using the $16 \mathrm{~S}$ rRNA gene amplicon sequencing via the Illumina MiSeq platform (Illumina, San Diego, CA) to determine the differences in microbial communities between the core and rind regions of each cheese. The different types of cheese and their various treatments were compared with one another to better understand which microbial populations affect the properties of cheese.

\section{MATERIALS AND METHODS}

\section{Cheese Sampling}

A variety of cheeses were obtained from the Arbuthnot Dairy Center at Oregon State University (Corvallis; Supplemental Figure S1; https://doi.org/10.3168/ jds.2019-17455). All cheese samples were produced using raw milk pasteurized at $65^{\circ} \mathrm{C}$ for $30 \mathrm{~min}$, and subsequently cooled to $32^{\circ} \mathrm{C}$. Different starter cultures were used depending on cheese type: Lactococcus lactis ssp. lactis biovar diacetylactis, Lc. lactis ssp. lactis, Lc. lactis ssp. cremoris, and Streptococcus thermophilus for Cheddar cheese; S. thermophilus and Lactobacillus delbrueckii ssp. bulgaricus for provolone; and Lc. lactis ssp. lactis, Lc. lactis ssp. cremoris, S. thermophilus, Lb. delbrueckii ssp. lactis, Lb. helveticus, and Lb. delbrueckii ssp. lactis without the addition of propionic acid bacteria for Swiss type cheese. Additionally, the starter cultures were incubated at $32^{\circ} \mathrm{C}$ for $1 \mathrm{~h}$ and rennet was added to coagulate the curd. After curd formation, the curds were cooked (Cheddar and Swiss: 32 to $40^{\circ} \mathrm{C}$ for $45 \mathrm{~min}$; provolone: $50^{\circ} \mathrm{C}$ for $30 \mathrm{~min}$ ). Using $4.0 \%$ (wt/ wt) of curd weight, dry salt was added to Cheddar and provolone cheeses and transferred to a mold to produce hard cheeses. Swiss cheese was formed hard cheese through a mold and transferred to a $25 \%$ saturated salt brine solution for $20 \mathrm{~h}$. Afterward, cheeses were sealed in vacuum packaging and stored at $4^{\circ} \mathrm{C}$ for 3 to 6 mo.

To provide flavor and modify the quality, cheese was soaked in beverages including pinot noir [wine, $14 \%$ alcohol by volume (ABV)], hard apple cider (cider, 7\% ABV), and porter (dark beer, $5 \%$ ABV). Fresh cheese blocks were soaked in their respective beverages at room temperature for $48 \mathrm{~h}$. After $48 \mathrm{~h}$, the cheeses were removed from the beverages and allowed to air dry at room temperature for $3 \mathrm{~h}$ until aerobic microorganisms can be grown. Traditional smoking methods were also applied to change the properties of Cheddar, provolone, and Swiss type cheese. Cheeses were smoked at $30^{\circ} \mathrm{C}$ for $6 \mathrm{~h}$ using applewood. Beverage-soaked cheese and smoked cheese samples were sealed with vacuum packaging and stored at $4^{\circ} \mathrm{C}$ for 3 to 6 mo. Finally, cheeses were divided into 3 primary groups: (1) Cheddar, (2) provolone, and (3) Swiss. The Cheddar cheeses were subdivided into plain, smoked, and pinot noir-, cider-, and porter-soaked, whereas provolone and Swiss only included plain and smoked type cheese. Samples were obtained from the core and rind regions of each cheese. Equal parts of rind and core regions were mixed to generate mixed regions of cheeses. Beverage-soaked 
cheese samples (pinot noir-, cider-, and porter-soaked Cheddar), and smoked cheese (Cheddar, provolone, and Swiss) were collected, taking the core, mixed, and rind regions separately. We collected only mixed region from plain cheese because no differences were observed between the core and rind regions of plain cheese, whereas smoking and soaking methods have a chance to alter the properties of the surface of the cheese. To avoid any technical errors, samples were obtained in triplicate from all of the cheese types, making a total of 63 samples collected. The DNA was extracted from these samples and a microbiome sequencing library was constructed to compare the differences between the core, rind, and mixed regions.

\section{DNA Extraction}

For DNA extraction, $1 \mathrm{~g}$ of core, rind, and mixed regions of each cheese were separated using a sterile razor blade. Cheese samples were homogenized with $9 \mathrm{~mL}$ of $1 \%$ tri-citric acid buffer $\left(\mathrm{C}_{6} \mathrm{H}_{7} \mathrm{Na}_{3} \mathrm{O}_{8}\right)$ while incubating in a 55 to $60^{\circ} \mathrm{C}$ water bath with vigorous vortexing. Extraction of DNA was performed on the homogenized cheese solutions using the DNeasy PowerFood Microbial Kit (Qiagen, Hilden, Germany) according to the manufacturer's instructions. The concentration of extracted DNA was measured via a Qubit 4 Fluorometer (Thermo Fisher Scientific, Waltham, MA), and subsequently diluted to achieve a final concentration of 10 $\mathrm{ng} / \mu \mathrm{L}$.

\section{S rRNA Gene-Based Library Preparation}

The sequencing library was prepared targeting the V4 region of the $16 \mathrm{~S}$ rRNA gene as previously reported by Kozich et al. (2013). Briefly, DNA amplicons were generated using a high-fidelity polymerase (AccuPrime, Invitrogen, Carlsbad, CA), and PCR products were confirmed using 1\% agarose gel electrophoresis. Amplified DNA samples were normalized using a SequalPrep Normalization kit (Life Technologies, Carlsbad, CA) according to the manufacturer's recommendation. Following normalization, $5 \mu \mathrm{L}$ of each normalized aliquot from each sample were combined to construct a pooled library and quantified using the KAPA Library Quantification kit (Kapa Biosystems, Woburn, MA). Finally, the library was diluted to the appropriate concentration and sequenced by the Illumina MiSeq.

\section{Microbiome Sequencing Via Illumina MiSeq}

A $20 \mathrm{n} M$ pool of the $16 \mathrm{~S}$ rRNA library and $20 \mathrm{n} M$ PhiX control V3 (Illumina) were mixed with $0.2 \mathrm{~N}$ of fresh $\mathrm{NaOH}$ and $\mathrm{HT} 1$ buffer (Illumina) to produce the final concentration of $6 \mathrm{p} M$. The resulting library was mixed with the PhiX control v3 (5\%, vol/vol, Illumina) and $600 \mu \mathrm{L}$ loaded on a MiSeq v2 (500 cycle, $2 \times 250$ bp) reagent cartridge for sequencing. The $16 \mathrm{~S}$ rRNA amplicon sequences are available at the Sequence Read Archive of the National Center for Biotechnology Information (https://dataview.ncbi.nlm.nih.gov/object/ PRJNA591223? reviewer =ktedeigveld5k4n89ljtkr3f0l) under SUB6594737.

\section{Data Analyses}

Both demultiplexed R1 and R2 raw sequences were acquired directly from the Illumina BaseSpace website, and sequences were analyzed using the Quantitative Insights Into Microbial Ecology 2 (QIIME 2, version 2018.11) open source pipeline (Bolyen et al., 2019). Demultiplexed sequences were joined and denoised for quality control using the DADA2 scripts available in QIIME 2 (v. 2018.11) to cluster operational taxonomic units (OTU) at 100\% sequence similarity with default parameters and generate a feature table for further analysis. The processed sequencing data were assigned a taxonomy and aligned to the Greengenes reference database (v. 13.8; http://greengenes.lbl.gov) at $99 \%$ sequence similarity (McDonald et al., 2012). For further statistical analysis and visual exploration, an OTU table with taxa in plain format and metadata file were uploaded to the MicrobiomeAnalyst tool available at http://www.microbiomeanalyst.ca (Dhariwal et al., 2017). Linear discriminant analysis (LDA) of effect size (LEfSe) was applied to determine the most discriminant taxa among different cheese samples based on the relative abundance. The LDA score, which uses statistical significance and biological relevance to find biomarker genes, was set to a default value of 2.0 (Segata et al., 2011).

\section{Predicted Functional Properties of Cheese Microbiome}

The functional potential of microbiome data from different types of cheese samples was predicted based on the 16S rRNA data using Piphillin (with 97\% identity cut-off; Iwai et al., 2016) and phylogenetic investigation of communities by reconstruction of unobserved states 2 (PICRUSt2) based on the Kyoto Encyclopedia of Genes and Genomes (KEGG) database (Langille et al., 2013). The predicted functional properties (PFP) tools based on 16S rRNA marker genes were used to predict the full genome sequence through comparing the fully identified and sequenced bacteria with unidentified bacteria using the phylogenetic tree (PICRUSt2) or directly compared with each other (Piphillin). Sequences 
then were compared with the assigned predicted full genome sequencing data within the KEGG or BioCyc reference database to assign functional properties. While PICRUSt2 requires the Greengenes database and preprocessed data from QIIME 2 pipeline, the Piphillin tool does not require any pre-processed data and support the KEGG and BioCyc reference databases (Iwai et al., 2016; Douglas et al., 2018). Statistical analysis of metagenomic profiles (STAMP) was used to identify microbial relevant functions between the 9 different types of cheese, and it also can be used to generate principal component analysis (PCA) analysis based on the KEGG orthology from Piphillin and PICRUSt2 analyses (Parks et al., 2014).

\section{RESULTS}

\section{Taxonomic Analysis}

A total of 4,675,187 sequencing reads were generated from the 63 cheese samples collected in this study, which included 9 different types of cheese (plain, smoked, ci- der-, porter-, and pinot noir-soaked Cheddar, plain and smoked provolone, and plain and smoked Swiss). The mean value for the frequency of sequences per sample was 71,081 reads/sample after analysis with QIIME 2. A total of 225 OTU were identified and included 86 OTU at the genus level. The processed sequencing data were compared with the Greengenes reference database (13.8; http://greengenes.lbl.gov; McDonald et al., 2012). In the taxonomic analysis, all data were analyzed at genus level. Streptococcus spp., Lactococcus spp., unidentified Lactobacillaceae, and Lactobacillus spp. were the most abundant taxa identified among all the cheese samples (Figure 1) and the rest of the OTU were categorized as others (Figure 1 and Supplemental Table S1; https://doi.org/10.3168/jds.2019-17455).

The composition of the cheese microbiome was largely dependent on the starter culture used. Lactococcus lactis ssp. lactis biovar diaceylactis, Lc. lactis ssp. lactis, Lc. lactis ssp. cremoris, and S. thermophilus spp. were used as starter cultures in Cheddar cheese production, while provolone starter cultures were composed of $S$. thermophilus and Lb. delbrueckii ssp. bulgaricus, and

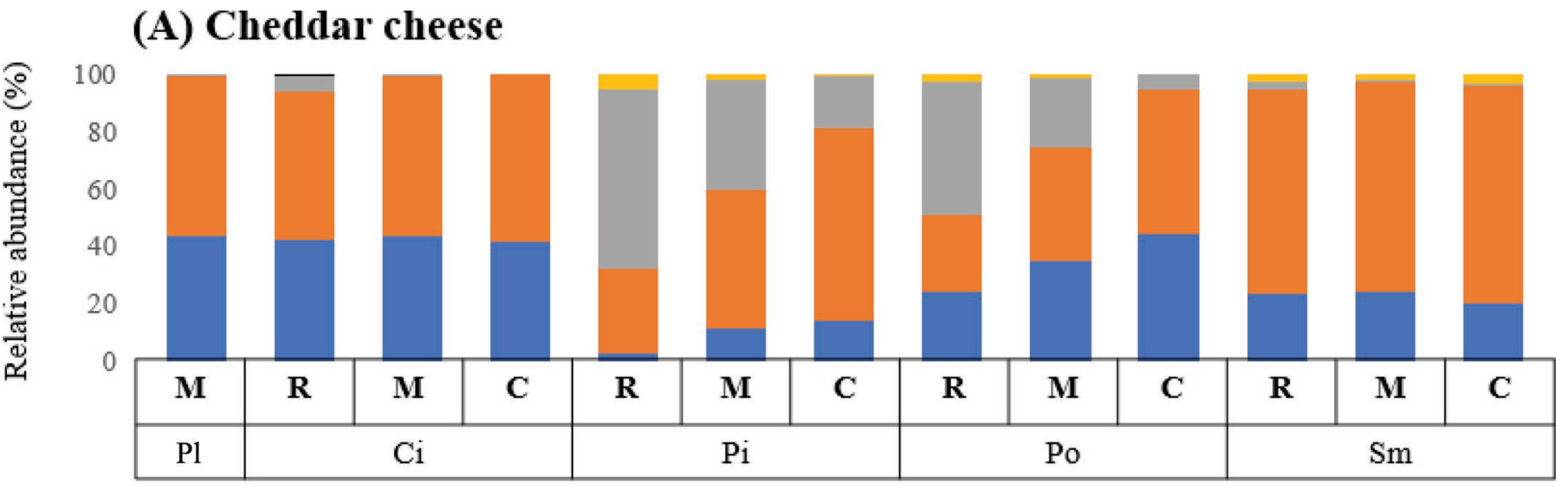

(B) Provolone cheese

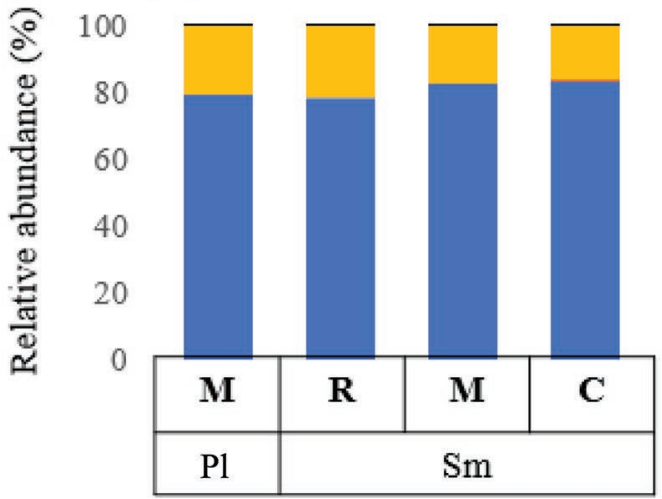

(C) Swiss cheese

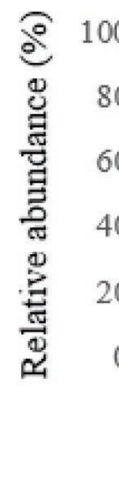

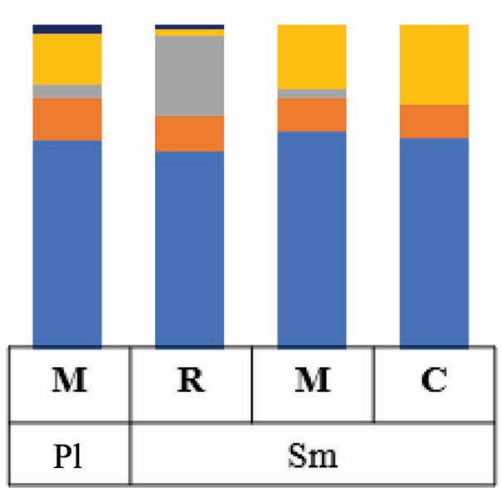

Streptococcus

Lactococcus

Lactobacillaceae

(Family level)

Lactobacillus

Others

Figure 1. Genus level of relative abundance (mean value for triplicate) of the 4 most abundant bacteria (Streptococcus, Lactococcus, Lactobacillaceae, and Lactobacillus), which accounted for more than $1 \%$ in cheese samples. $\mathrm{Pl}=\mathrm{plain}$; Ci $=$ cider-soaked; Pi $=$ pinot noir-soaked; $\mathrm{Po}=$ porter-soaked; and $\mathrm{Sm}=$ smoked. Samples are separated by the mix $(\mathrm{M}=$ core and rind mixed), core $(\mathrm{C})$, and rind $(\mathrm{R})$ regions. 
Swiss cheese used Lc. lactis ssp. lactis, Lc. lactis ssp. cremoris, S. thermophilus, Lb. delbrueckii ssp. lactis, Lb. helveticus, and Lb. delbrueckii ssp. lactis at once with no additional propionic acid bacteria during manufacturing.

Streptococcus spp. were present in the highest percentages in most of cheese samples, ranging from 15 to $85 \%$ of the relative abundance (Figure 1 ). The only sample with a low relative abundance was the pinot noir-soaked Cheddar, where it ranged from 2 to $13 \%$ for both the core and mixed regions of the cheese. The average value for the rind region of the pinot noir-soaked Cheddar cheese was $2 \%$. The second lowest concentration was in the smoked Cheddar samples, where Streptococcus spp. comprised 19 to $24 \%$ of the organisms present. The provolone samples (plain and smoked) exhibited the highest abundance for Streptococcus spp., with values ranging from 78 to $83 \%$. All other samples showed between 23 to $67 \%$ of relative abundance, with most falling in the upper end of the range. In addition, the relative abundance of Streptococcus spp. in the core or mixed regions were higher than in the rind region.

The second most prevalent genus was Lactococcus spp., which was present in all samples with values ranging from 1 to $73 \%$ (Figure 1). Provolone included the fewest Lactococcus spp., with less than $1 \%$ in all samples. A likely explanation for this is the absence of Lactococcus spp. in the provolone starter culture, which contained S. thermophilus and Lb. delbrueckii ssp. bulgaricus. While the highest values reported for Lactococcus spp. were from the smoked Cheddar (71 to 76\%), all other Cheddar varieties contained only 27 to $67 \%$, and all Swiss cheese samples ranged from 9 to $13 \%$. Additionally, the abundance of Lactococcus spp. in the core and mixed regions was higher than the rind regions across all cheese samples. The prevalence of Lactobacillaceae family was dominant on the rind region of the porter- and pinot noir-soaked Cheddar cheeses (46 and $63 \%$, respectively) than core regions. This family was also identified on the rind of the smoked Swiss (24\%) as well as less abundant in the core region (Figure 1).

Lactobacillus spp. were less abundant than Streptococcus spp. and Lactococcus spp. across all samples, with values ranging from 0 to $22 \%$. Lactobacillus spp. were present in low abundance in plain Cheddar cheese samples (less than 0.1\%), and more prevalent in pinot noir-soaked (0 to $5 \%$ ), porter-soaked (0 to $2 \%$ ), and smoked (2 to $3 \%$ ) Cheddar cheeses. In addition, the relative abundance of Lactobacillus spp. in the rind region of pinot noir-soaked $(5 \%)$ and porter-soaked $(2 \%)$ Cheddar cheese was higher than in the core region $(0 \%)$. Compared with the Cheddar cheese, Swiss (2 to $24 \%$ ), and provolone (17 to $22 \%$ ) cheeses pos- sessed more Lactobacillus spp. The relative abundance of Lactobacillus spp. in smoked provolone was higher in the rind region $(22 \%)$ than the core region $(17 \%)$ of the same cheese, whereas in smoked Swiss it was higher in the core region (24\%) than the rind region $(3 \%)$.

\section{Alpha Diversity}

Alpha diversity of the microbial communities was assessed using the Chao1 and Shannon indexes (Figure 2). The Chaol (Figure 2A and 2B) indicates the microbial richness among the different types of cheese. No significant differences $(P<0.05)$ were observed between plain and smoked provolone or between plain and smoked Swiss cheese; however, the different types of cheese (Cheddar, provolone, and Swiss) had significant differences $(P<0.05)$. The richness (Chao1 index) of Swiss and smoked Swiss cheese (5 to 10) was higher than that of provolone and smoked provolone (4 to 7). The richness of plain, cider-soaked, and smoked Cheddar cheeses were low (5 to 10), whereas pinot noir- and porter-soaked Cheddar cheeses were high (8 to 10). Finally, the richness of all cheese samples showed high values in the rind region when compared with the core region, except for porter-soaked Cheddar cheese.

The Shannon index (Figure 2C and 2D) accounts for both richness and evenness of OTU. High values for diversity indicate more diverse communities. The Shannon index indicates that the rind is more diverse than the core across all cheeses. The Shannon index of provolone and smoked provolone (0.40 to 0.56$)$ were significantly lower $(P<0.05)$ than Swiss and smoked Swiss cheese (0.74 to 1.06). Smoked versus nonsmoked samples were not significantly different for any of the cheeses. The Shannon index of Cheddar cheese differed significantly $(P<0.05)$ depending on the treatment. The Shannon index of plain Cheddar (0.69 to 0.71), cider-soaked Cheddar (0.69 to 0.92), and smoked Cheddar $(0.67$ to 0.82$)$ cheese were significantly lower than pinot noir- (0.95 to 1.66$)$ and porter-soaked (0.84 to 1.76) Cheddar cheeses.

\section{Beta Diversity}

When beta diversity parameters were used to assess the microbiome structure of the cheese samples, significant differences were found between the core and rind regions. Bray-Curtis models (Figure 3A) derived from the data input into MicrobiomeAnalyst (https:/ /www.microbiomeanalyst.ca) showed obvious grouping between samples. According to the dendrogram (Figure 3B), clusters were identified by the types of cheese (provolone, Swiss, and Cheddar cheese). 
(A)

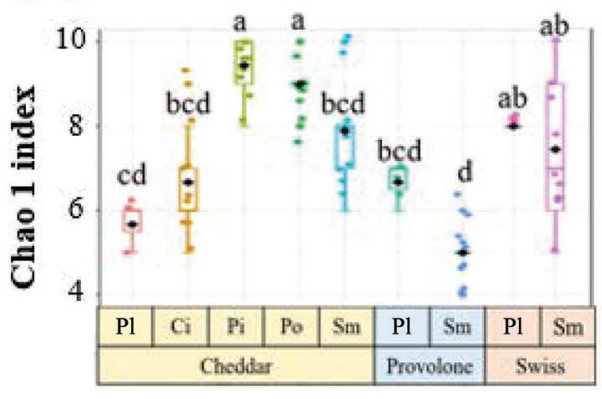

(C)

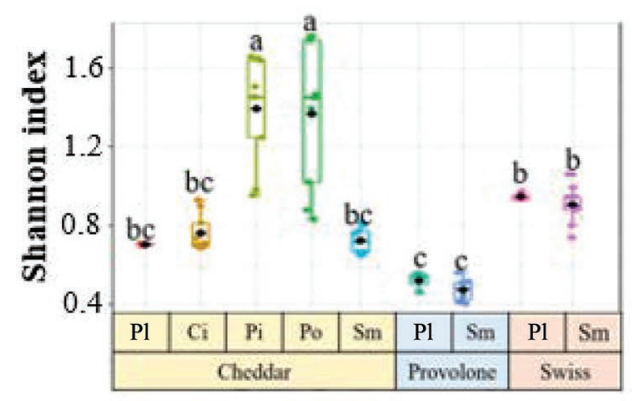

(B)

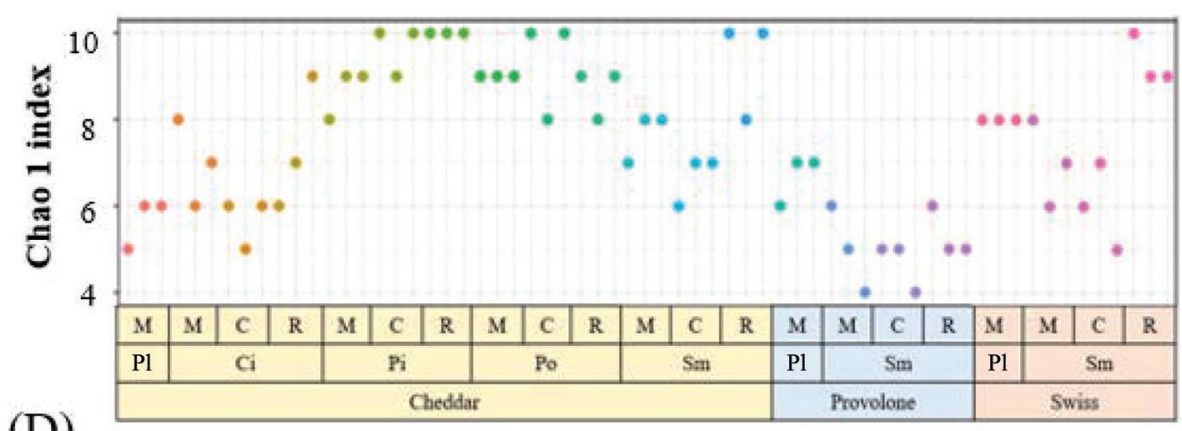

(D)

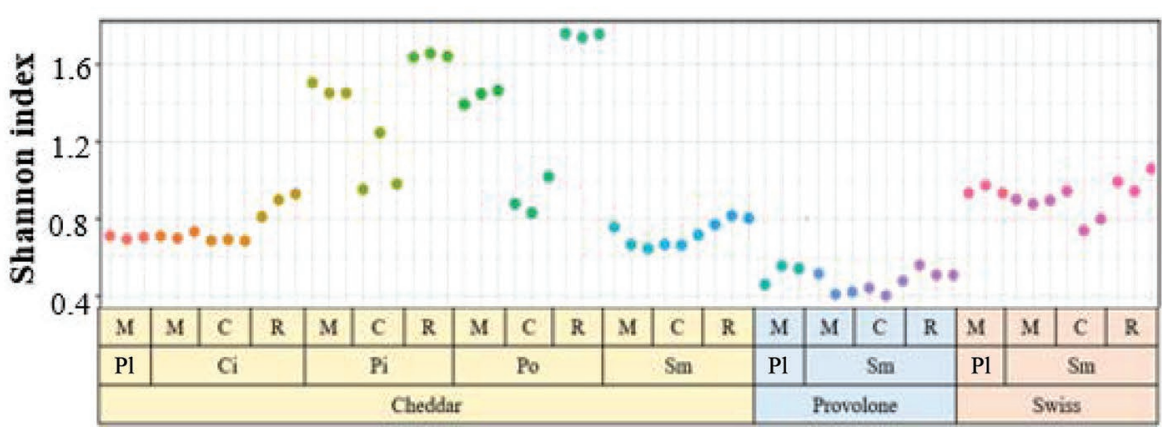

Figure 2. Alpha diversity of different types of cheese. The Chao1 index (Figures 2A and 2B) and Shannon index (Figures 2C and 2D) of 9 cheese types $(\mathrm{Pl}=$ plain cheese; $\mathrm{Ci}=$ cider-soaked cheese; $\mathrm{Pi}=$ pinot noir-soaked cheese; $\mathrm{Po}=$ porter-soaked cheese; and $\mathrm{Sm}=$ smoked cheese $)$. Samples are separated by the type of cheese (Figures 2A and 2C) or type of cheese with mix (M), core (C), and rind (R) regions (Figures 2B and 2D). Boxes in the plots represent the interquartile range (IQR) between first and third quartiles, respectively. The horizontal line and dot in the box indicate the median and mean value, respectively. The whiskers indicate the lowest and highest value within 1.5 times the IQR from the first and third quartiles, respectively. a-d: Letters within each figure indicate difference at the $95 \%$ significance level $(P<0.05)$.

\section{Identification of Biomarkers}

Biomarker bacteria from the different types of cheese were assessed using LEfSe. When LEfSe was applied to the microbiota data of 9 different types of cheese, 34 different taxonomic clades with an LDA score higher than 2.0 were found (Figure 4) and a total of 10 biomarkers were identified at the genus level. For instance, 19 OTU in plain Swiss cheese, 1 OTU in smoked Swiss cheese, 6 OTU in smoked provolone, 1 OTU in smoked Cheddar cheese, 1 OTU in provolone, 3 OTU in portersoaked Cheddar, 1 OTU in pinot noir-soaked Cheddar, and 2 OTU in plain Cheddar cheese were identified as the representative bacteria among the cheese samples (Table 1).

\section{Predictive Metagenomics Profiling}

The microbiome functioning potential of cheeses was predicted based on predictive metagenomics profiling to compare the different bacterial functions among the 9 cheese samples. Several predictive pathways were sig- nificantly enriched in the microbiome data, giving 11 different functions from the Piphillin and PICRUSt2 pipelines. The functions were carbohydrate metabolism, AA metabolism, nucleotide metabolism, metabolism of cofactors and vitamins, energy metabolism, lipid metabolism, metabolism of other AA, glycan biosynthesis and metabolism, metabolism of terpenoids and polyketides, xenobiotics biodegradation metabolism, and biosynthesis of other secondary metabolites (Figure 5, Tables 2 and 3). Additionally, functional property differences between 9 varieties of cheese samples were analyzed and compared through a PCA plot (Figure 6). As can be seen in the PCA plot, functional properties were influenced by cheese type. For example, provolone clustered with smoked provolone whereas Swiss clustered with smoked Swiss, demonstrating similar functional properties. Additionally, porter-soaked and pinot noir-soaked cheeses clustered together, whereas cider-soaked and smoked Cheddar cheese each clustered separately. The primary carbohydrate metabolized by these organisms is lactose, which is fermented to produce lactic acid (Figure 7). Among carbohydrate metabolism, galactose 
metabolism (10.06\%) and glycolysis/gluconeogenesis $(21.82 \%)$ were related to lactic-acid-producing mechanisms (Table 4).

\section{DISCUSSION}

The cheese microbiome plays a key role in determining the organoleptic and physicochemical properties of cheese, affecting both its quality and safety (Yeluri Jonnala et al., 2018). The development of next-generation sequencing technologies has allowed the characterization of microbial communities in cheeses collected around the world to become an active area of research (DugatBony et al., 2016). Wolfe et al. (2014) sequenced 137 different cheese rind communities from 10 countries to identify the dominant bacterial community members. De Filippis et al. (2014) delineated the microbial community properties of 3 popular Italian cheeses, mozza-

\section{(A) PCoA plot}

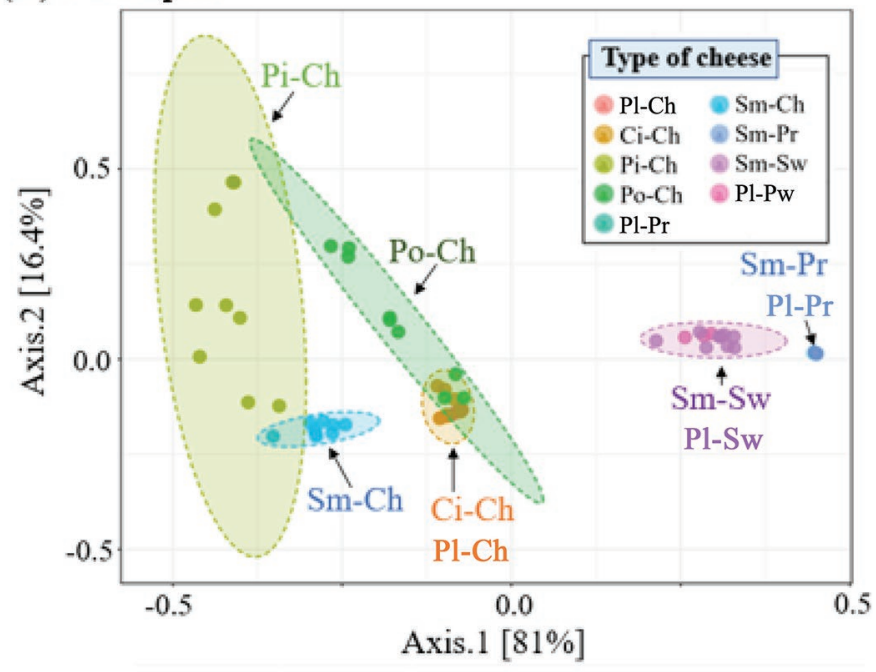

(B) Dendrogram

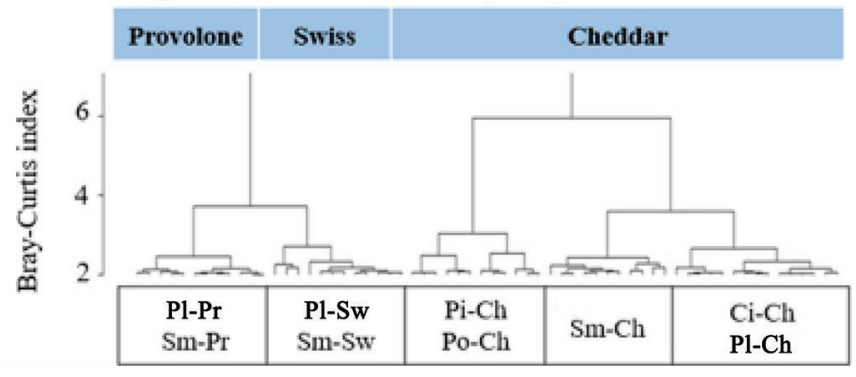

Figure 3. (A) Bray-Curtis distance principal coordinate analysis $(\mathrm{PCoA})$ plot shows groupings of similar cheese varieties $(\mathrm{Ch}=$ Cheddar; $\mathrm{Pl}=$ plain; $\mathrm{Ci}=$ cider-soaked; $\mathrm{Pi}=$ pinot noir-soaked; $\mathrm{Po}=$ porter-soaked; $\mathrm{Sm}=$ smoked; $\mathrm{Pr}=$ provolone; and $\mathrm{Sw}=$ Swiss). All replicates fell within a range of one another, with the Cheddar cheese varieties having the largest amount of variance and (B) dendrogram of represented taxonomic relationships. rella, Grana Padano, and Parmigiano Reggiano. In the present study, we analyzed the microbial populations of 9 different cheeses within 3 varieties, which were acquired from the Arbuthnot Dairy Center at Oregon State University (Corvallis). The high-throughput sequencing approach was used to generate a list of 225 OTU, which were processed using the Greengenes database. Of these 225 OTU, only 9 were found to represent $1 \%$ or more of the overall microbial community. The dominant OTU present in cheeses were identified as Streptococcus spp., Lactococcus spp., an unspecified group of the family Lactobacillaceae, and Lactobacillus spp. The 2 most abundant OTU identified were Streptococcus spp. and Lactococcus spp., both of which are commonly used as cheese starter cultures.

Cheeses made with combined single strains of Lc. lactis and Lc. cremoris as starters develop desirable flavors of fermented dairy products. In this study, Lactococcus was used as a starter lactic acid bacteria for all the cheese samples (Schleifer et al., 1985). The species $S$. thermophilus is widely used for the preparation of several dairy products, such as fermented milks, yogurts, and cheeses (Mora et al., 2002; Dugat-Bony et al., 2016). Lactic acid bacteria (LAB) are a heterogeneous group of microorganisms that convert carbohydrates into lactic acid. They contain both pathogenic and beneficial organisms, including $S$. thermophilus and $L c$. lactis, which are used in milk fermentation (Bolotin et al., 2001). There are 2 subspecies of Lc. lactis: Lc. lactis ssp. lactis and Lc. lactis ssp. cremoris, which were originally classified as $S$. lactis and $S$. cremoris (Schleifer et al., 1985).

Of the OTU present at over $1 \%$ of the total microbial composition, some were specific to certain cheeses in a genus level. For example, Lactobacillus spp. were found in all samples of Swiss cheese. According to Takano (2002), Lb. helveticus, which is used as starter bacteria for producing Swiss cheese, is responsible for the proteolytic generation of antihypertensive peptides during the fermentation of milk. Lactobacillus spp. were found throughout all Swiss and provolone cheese samples, ranging from a low of 1 to $3 \%$ on the rind region of smoked Swiss cheese to a high of $24 \%$ in the core region of the smoked Swiss cheese.

To make the Cheddar cheeses for this study, Lactococcus spp. and Streptococcus spp. were used as starter cultures. Lactobacillaceae were present in high abundance (46 and 65\%) on the rind regions of the porter- and pinot noir-soaked Cheddar cheeses; however, they were found at low abundance in plain $(0.3 \%)$ and cider-soaked (5\%) Cheddar cheeses. Lactobacillaceae are common nonstarter lactic acid bacteria (NSLAB). The origin of NSLAB is debated, but every cheese sample has NSLAB. Although raw milk is a significant 
source of NSLAB, other sources include environmental contamination or contamination during the cheese making process or storage (Gobbetti et al., 2015). Lactobacillaceae grow well in carbohydrate-containing substrates, such as dairy products, grain products, beer, and wine (Felis and Pot, 2014). Because the cheeses produced for this study were made using pasteurized milk, the native microbiota of raw milk could not be a major source of NSLAB. Though some organisms may survive during pasteurization, the production environment is likely the primary source of Lactobacillaceae in the untreated Cheddar cheese. It may be present only

(A)
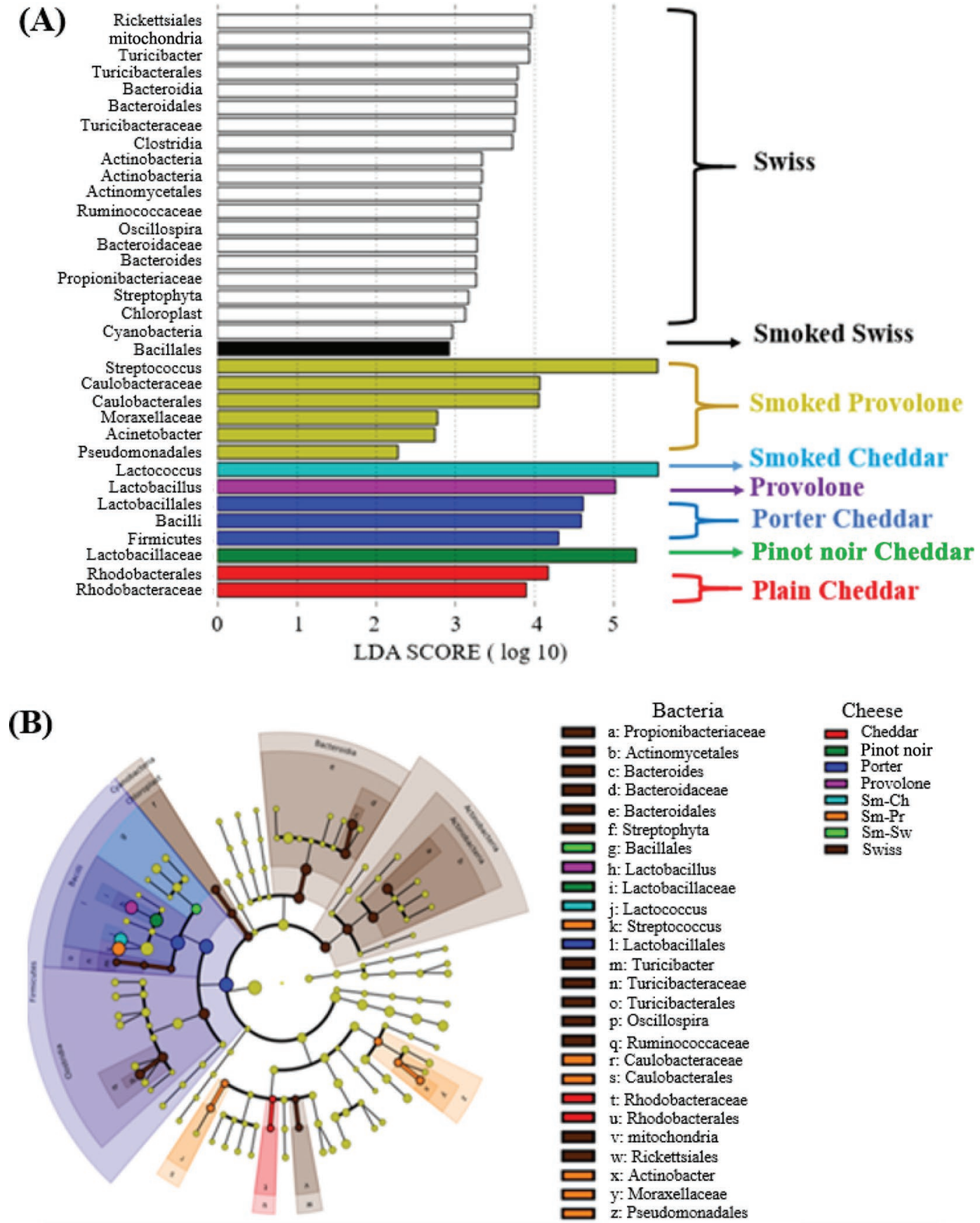

Figure 4. Taxonomic differences of cheese microbiota between 9 different types of cheese. (A) The taxa exhibit linear discriminant analysis $(\mathrm{LDA})$ significant differences $(P<0.01)$ among cheese samples $(\mathrm{Ch}=$ Cheddar; $\mathrm{Pl}=$ plain $; \mathrm{Ci}=$ cider-soaked; $\mathrm{Pi}=$ pinot noir-soaked; $\mathrm{Po}=$ porter-soaked; $\mathrm{Sm}=$ smoked; $\mathrm{Pr}=$ provolone; and $\mathrm{Sw}=\mathrm{Swiss})$, up to genus level, and (B) taxonomic cladogram obtained from linear discriminant analysis effect size analysis of $16 \mathrm{~S}$ rRNA gene sequencing. 
in low levels in the cheeses as there are low levels in the production environment or competition from starter cultures. Higher levels of Lactobacillaceae in the porterand pinot noir-soaked Cheddar cheeses were expected, as it has been noted that these organisms can grow in beer and wine. The soaking treatments likely inoculate the cheese surface with these organisms. Following this logic, one would expect to see higher levels of Lactobacillaceae in the rind of the cider-soaked samples as well; however, this was not the case. This may be due to the addition of a large quantity of salt to the cider to combat $\mathrm{pH}$ problems.

Differences were found in the microbial communities present in the rind versus the core regions, with the rinds showing a higher level of diversity than the core regions. The rind microbiome further varied based on the type of rind, degree of aging, and environmental conditions (Yeluri Jonnala et al., 2018). While the cheese samples from Wolfe et al. (2014) made a distinctive rind microbiota through exposing cheese surface in the air during aging, beverage-soaked cheese samples in this study did not exhibit noticeable rind formation.
Beverage-soaked cheese samples have exposed to the air for $3 \mathrm{~h}$ and ripened with a vacuum-sealed packaging for 3 to $6 \mathrm{mo}$ at $4^{\circ} \mathrm{C}$. This might inhibit the development of proliferative rind microbiota compared with the previous Wolfe et al. (2014) study. However, we found that beverage-soaked treatment on cheese surface can lead more profound microbial variations between the core and rind regions, which matched with the result from the previous study (Wolfe et al., 2014). For example, significant differences in microbial richness between the core and rind were seen in smoked cheeses. According to De Filippis et al. (2016) and Wolfe et al. (2014), the lower water activity and higher oxygen concentration can alter the microbial communities between the core and rind regions.

Soaking into the different beverages (cider, porter, and pinot noir) can change the microbial composition and diversity of cheese. The relative abundance of unidentified Lactobacillaceae was increased after soaking in the beverage, and all results indicated the relative abundance of Lactobacillaceae from rind regions was higher than the mixed and core regions. In the pre-

Table 1. Relative abundance and potential pathogen of biomarkers identified through linear discriminant analysis effect size

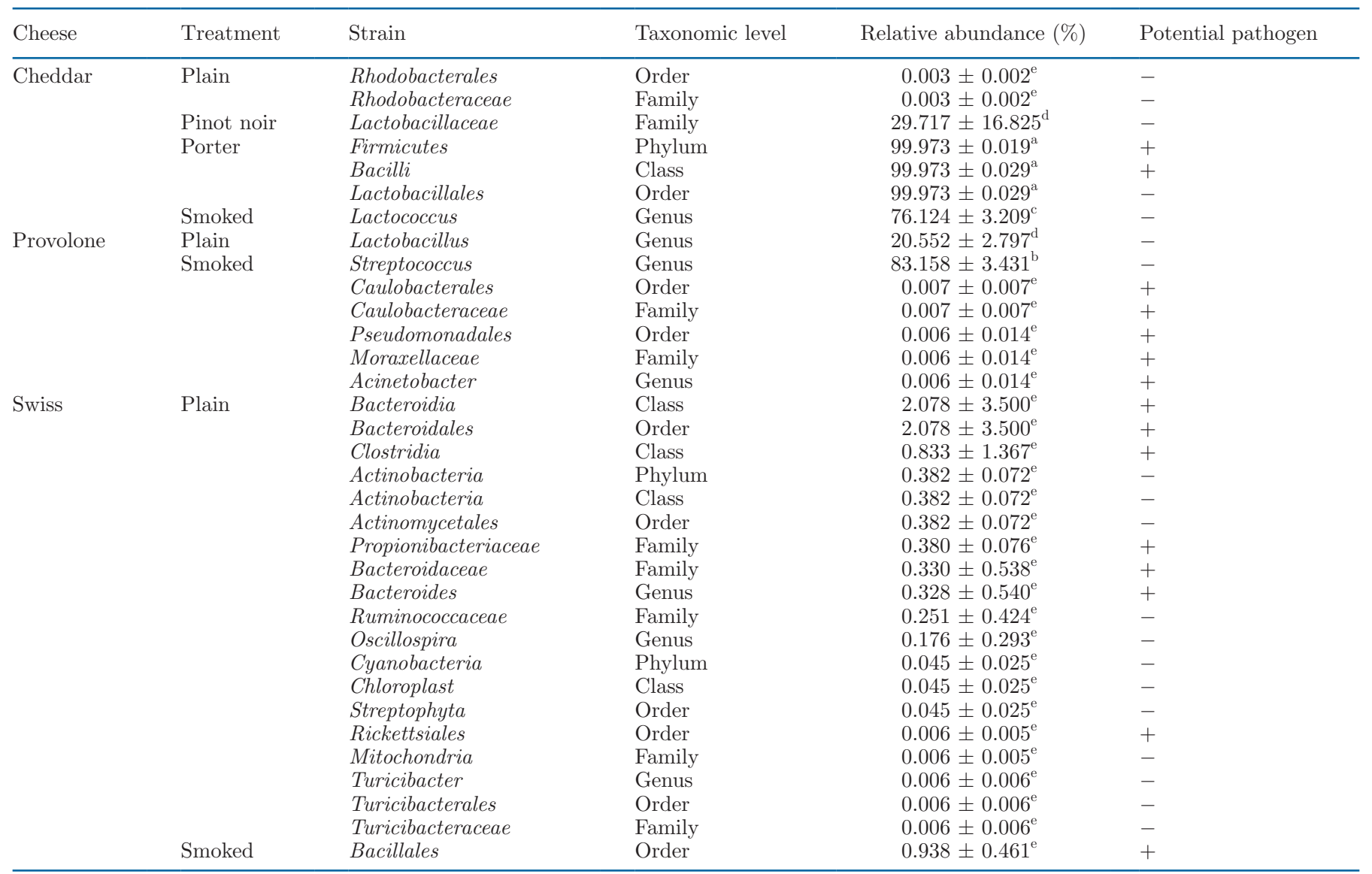

\footnotetext{
${ }^{\mathrm{a} e}$ Superscript letters within a row indicate differences at the $95 \%$ significance level $(P<0.05)$.
} 
(A) Carbohydrate metabolism

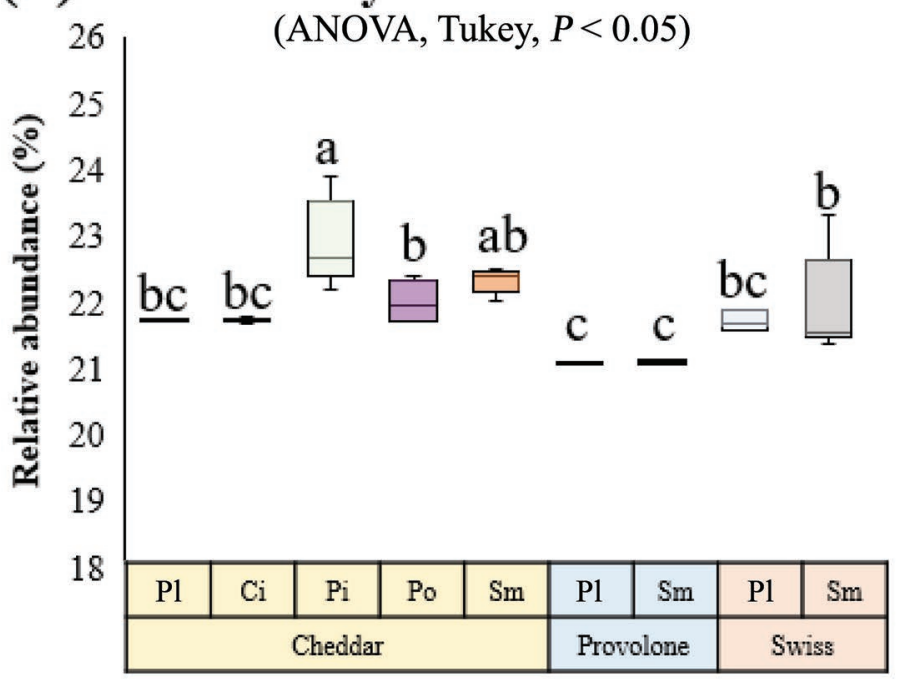

Amino acid metabolism

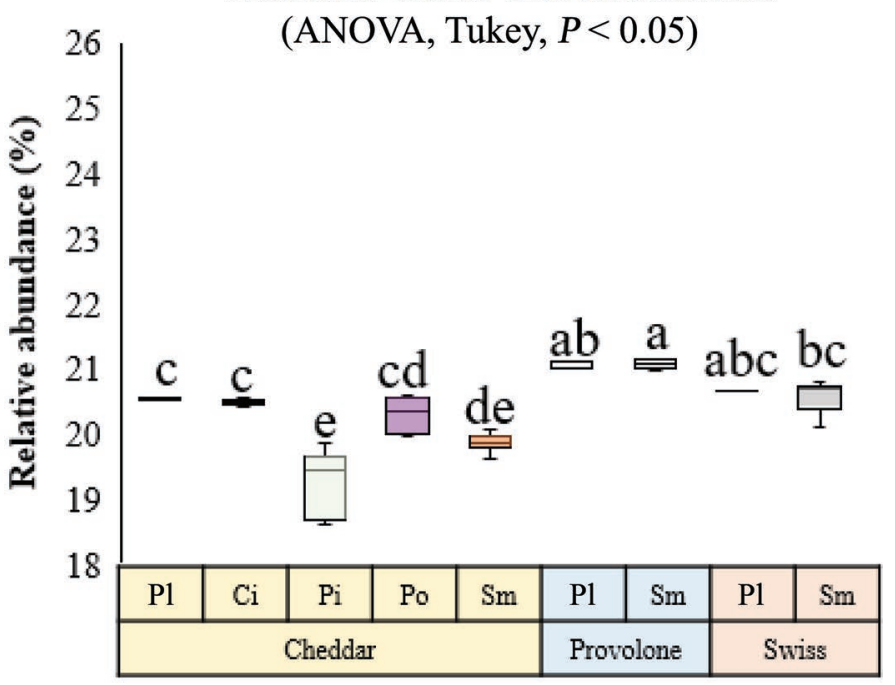

(B) Carbohydrate metabolism

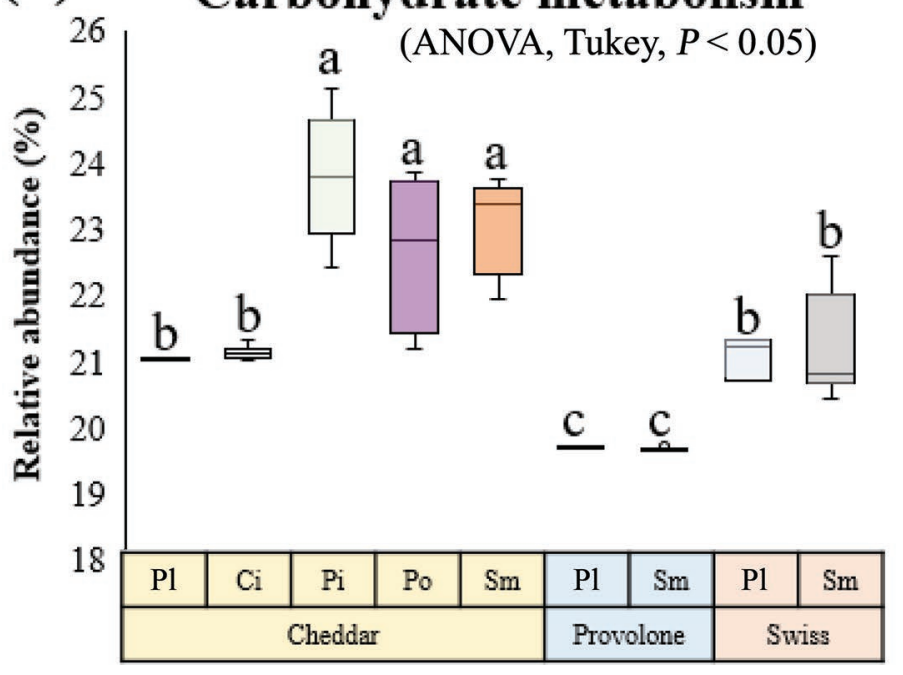

Amino acid metabolism

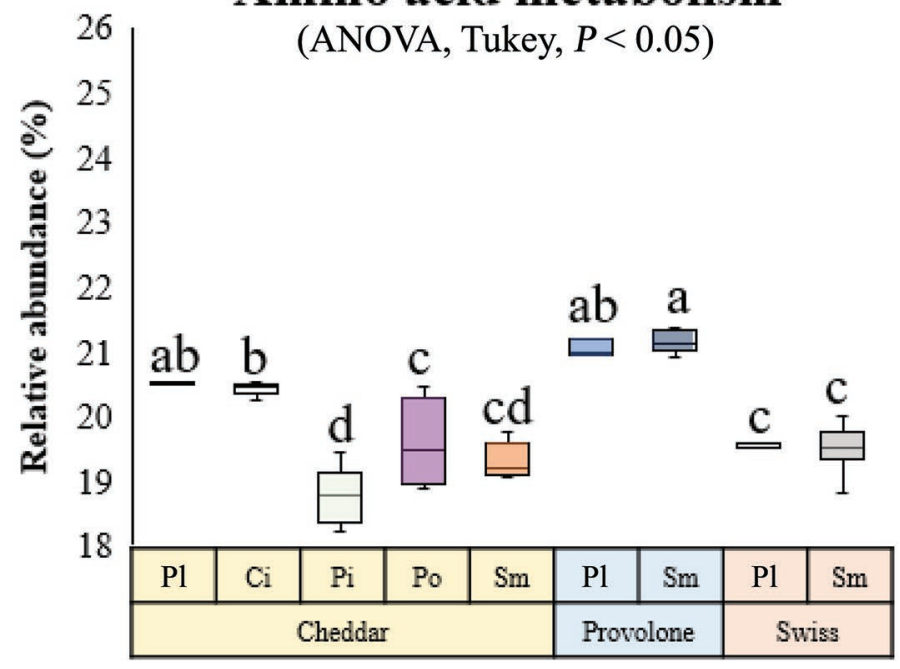

Figure 5. Box plot for predicted relative abundance of carbohydrate and AA metabolism annotated genes showing differences in cheese microbiota among 9 different types of cheese $(\mathrm{Pl}=$ plain; $\mathrm{Ci}=$ cider-soaked; $\mathrm{Pi}=$ pinot noir-soaked; Po $=$ porter-soaked; and $\mathrm{Sm}=$ smoked $)$ from (A) Piphillin (Iwai et al., 2016) and (B) phylogenetic investigation of communities by reconstruction of unobserved states 2 (PICRUSt2). Boxes in the plots represent the interquartile range (IQR) between first and third quartiles, respectively. The horizontal line in the box indicates the median. The whiskers indicate the lowest and highest value within 1.5 times the IQR from the first and third quartiles, respectively. a-e: Letters within each figure exhibit difference at the $95 \%$ significance level $(P<0.05)$.

vious study, Cousin et al. (2017) analyzed the microbial property of hard apple cider that main bacterial community was identified to the Lactobacillaceae and Acetobacteraceae family. It is related to our result that the increase of relative abundance of Lactobacillaceae in the rind region of cider-soaked Cheddar cheese. Porter beer is a red-brown acidic beer that commonly uses yeast and LAB as starter cultures. Pediococcus damnosus and Lactobacillus belong to Lactobacillaceae family were identified to the most common bacterial group found in the maturation phase of porter beer (Bokulich and Bamforth, 2017). The high relative abundance of Lactobacillaceae in the rind region of porter-soaked Cheddar cheese corresponded to the previous study. Malolactic fermentation converts malic acids to lactic acids, led by Oenococcus oeni and other LAB. These are important bacterial strains to produce red wine flavor, and LAB occupied a high portion of microbial populations in red wine (Bokulich et al., 2016). The increase of Lactobacillaceae in pinot noir-soaked Cheddar cheese in this study originated from pinot noir wine. Based on the previous studies, the changes of microbial popula- 


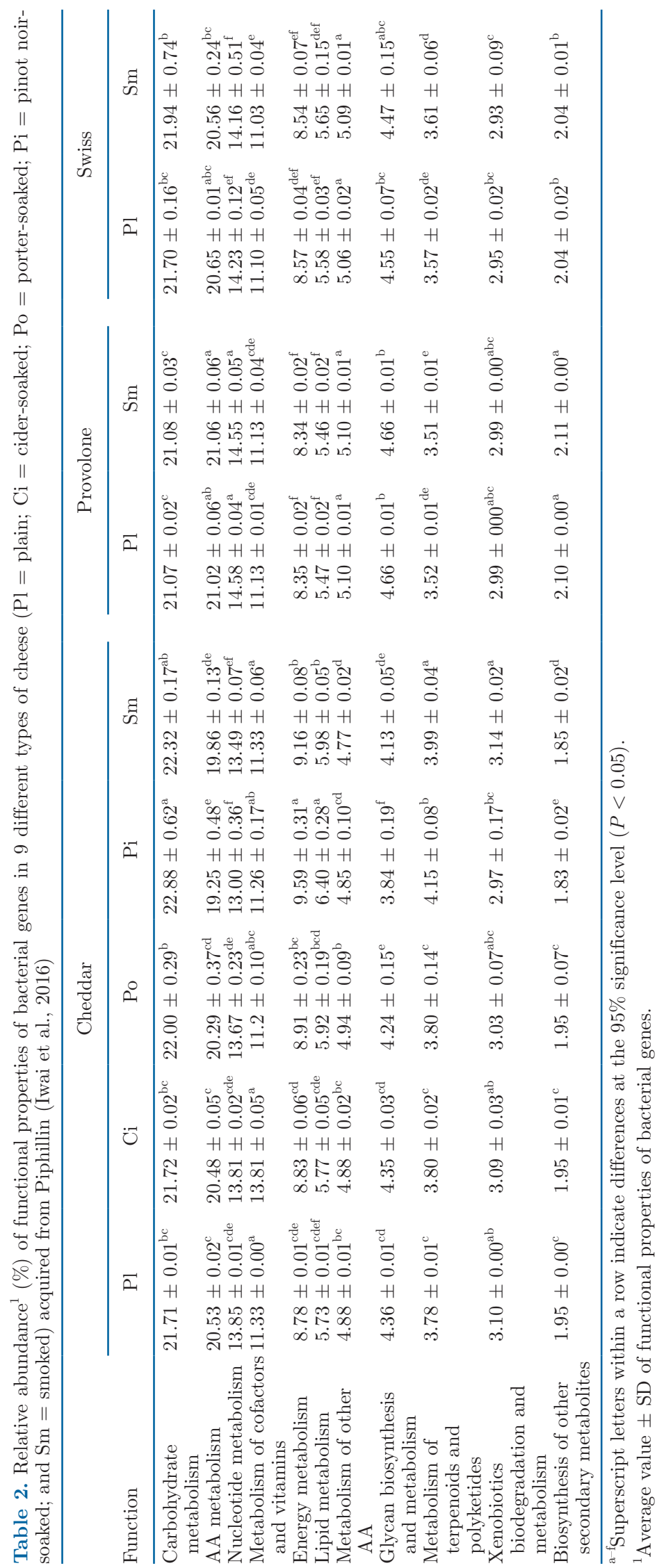




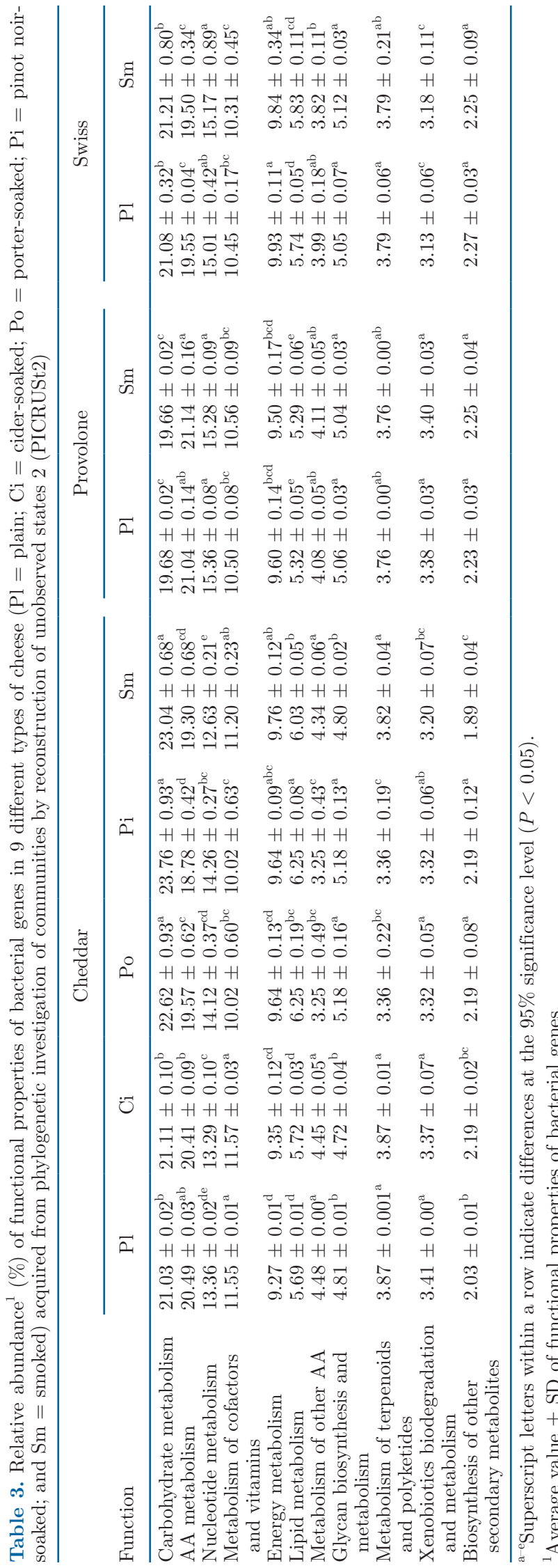

tions in the rind and core regions of cheese might be directly influenced by soaking materials.

According to the previous studies, the microbial populations of cheese were significantly determined by cheese making and ripening processes (Porcellato and Skeie, 2016; De Filippis et al., 2016). Porcellato and Skeie (2016) found that scalding temperature (37 and $39^{\circ} \mathrm{C}$ ) during ripening up to $3 \mathrm{mo}$ is the most important factor for the establishment of Dutch-type cheese microbiome. A high number of Lactobacillus spp. was detected during ripening at high scalding temperature $\left(39^{\circ} \mathrm{C}\right)$. In this study, because all cheeses were aged under same conditions up to 3 to 6 mo, the aging condition was not considered the factor that might affect the microbiome of different types of cheese.

Based on the Shannon index, no significant differences $(P>0.05)$ were observed between smoked and nonsmoked Cheddar, provolone, and Swiss cheeses. This indicates that smoking did not alter the microbial diversity of cheese because they were not exposed to other environmental microbes. However, the Shannon index of pinot noir- (1.39), and porter-soaked (1.37) Cheddar cheeses were significantly increased $(P<0.05)$ compared with the plain Cheddar cheese $(0.70)$, indicating that soaking in pinot noir or porter increased the microbial diversity. Additionally, the Shannon index of the rind regions was higher than the core regions across all samples. The richness increased in the rind region may be partly due to the availability of oxygen, which allows the growth of aerobic bacteria that cannot survive in the core (Donnelly, 2014). Interaction with environmental sources is another factor that may increase microbial diversity in the rind region. The rind is contact with the surface of cheese throughout production and aging, and can readily be contaminated with microbes from the environment. On the other hand, the core region can be preserved and is composed of organisms present at the time of shaping.

Analysis of the beta diversity indicated that the various groups of cheese were strongly related to one another in microbial composition. The same group of cheese samples was clustered on Bray-Curtis principal coordinate analysis plots (Figure 3). Both pinot noirand porter-soaked Cheddar cheeses showed a noticeable difference between the core and rind regions compared with other groups of cheese. The porter- and pinot noirsoaking treatments changed the beta diversity in the Cheddar cheeses. Moreover, the dendrogram indicated that each group of cheese exhibited high similarity in microbial composition. Provolone and Swiss cheeses were especially similar, whereas the Cheddar cheese samples did not cluster with the other 2 varieties of cheese. According to previous studies (Wolfe et al., 2014; Dugat-Bony et al., 2016), the microbial diversity 
of cheese was significantly influenced by processing, type of cheese, and moisture content.

Further analysis of the cheese microbiome with LEfSe (Figure 4) found significant differences in bacterial abundance among different types of cheese. Biomarker or biological markers imply a measurable indicator of a certain biological state or condition. The LEfSe is a tool used to find biomarkers between 2 or more groups using relative abundance. To identify biomarkers in cheese samples, LEfSe was used to compare the relative abundance of bacteria from each cheese samples and find bacterial strains that were specific and in high
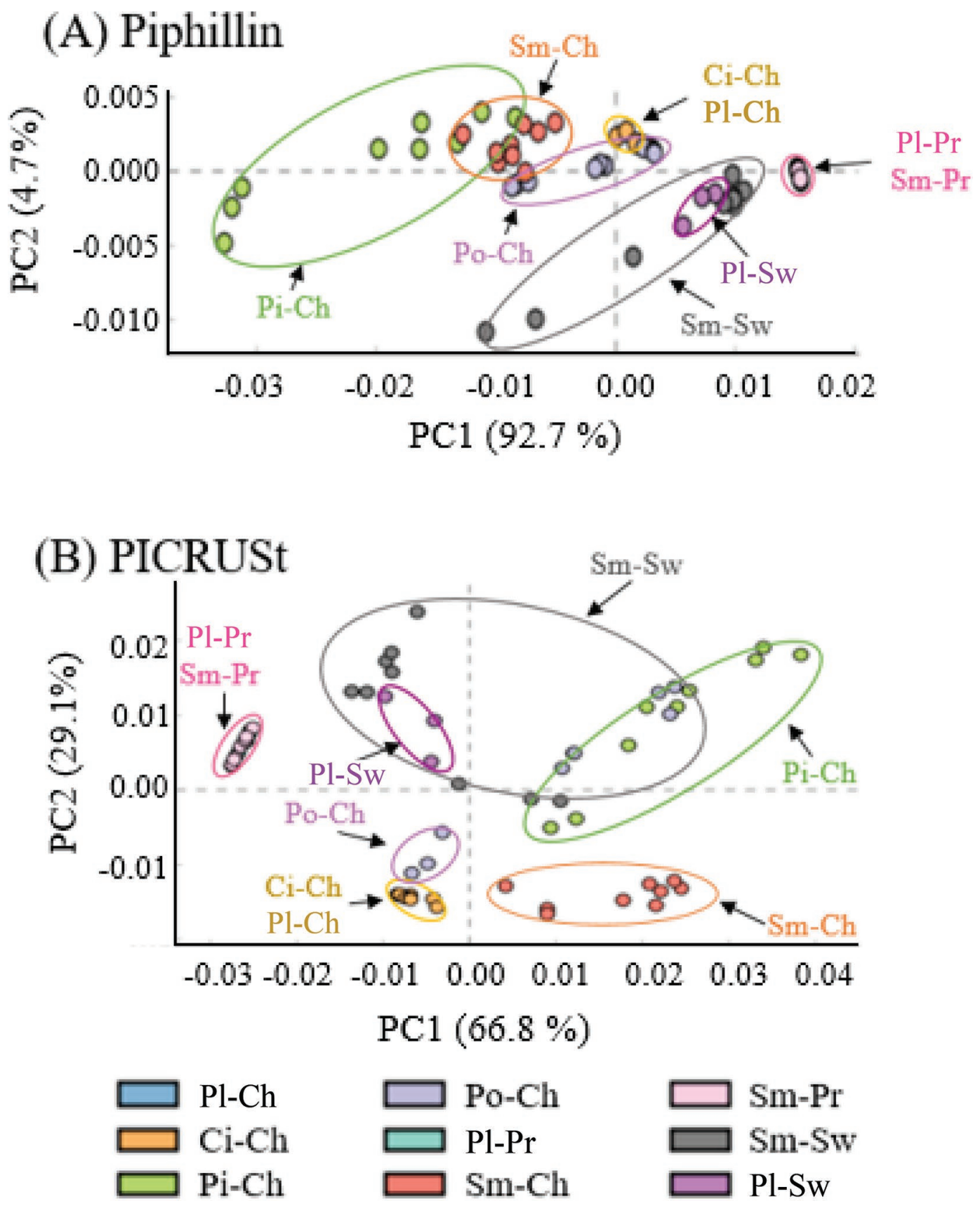

Figure 6. Principal component (PC) analysis plot for functional annotated gene differences of cheese microbiota between 9 different types of cheese $(\mathrm{Ch}=$ Cheddar; $\mathrm{Pl}=$ plain cheese $; \mathrm{Ci}=$ cider-soaked cheese; $\mathrm{Pi}=$ pinot noir-soaked cheese $; \mathrm{Po}=$ porter-soaked cheese; $\mathrm{Sm}=$ smoked cheese; $\mathrm{Pr}=$ provolone; and $\mathrm{Sw}=$ Swiss) from (A) Piphillin (Iwai et al., 2016) and (B) phylogenetic investigation of communities by reconstruction of unobserved states 2 (PICRUSt2). 
abundance in each cheese. The biomarker is widely used in the clinical field as an indicator to diagnose a target sample (Segata et al., 2011). Biomarkers present at more than $1 \%$ in the cheese samples included Streptococcus spp., Lactococcus spp., Lactobacillaceae, and Lactobacillus spp., which were identified as biomarkers in the smoked provolone, smoked Cheddar, pinot noir-soaked Cheddar, and provolone cheeses, respectively. Although Streptococcus spp. were used as starter cultures for all the 3 types of cheese (Cheddar, provolone, and Swiss), the relative abundance of Streptococcus spp. was the highest in provolone. In provolone cheese, the smoking treatment decreased the relative abundance of Lactobacillus spp., whereas Streptococcus spp. increased. Similarly, Lactococcus spp. and Streptococcus spp., the predominant organisms in Cheddar cheeses, were affected by smoking. Smoking decreased the relative abundance of Streptococcus spp. and increased the relative abundance of Lactococcus spp. In the previous study (Majcher et al., 2011), the number of lactobacilli, lactococci, streptococci, and enterococci were decreased during the smoking process. Warm smoking $\left(25\right.$ to $35^{\circ} \mathrm{C}$ ) leads to an increase in phenolic compounds formed during the smoking process that are known to have bactericidal properties. Thus, this treatment may have affected the microbial diversity. However, the decreasing ratio of each bacteria was dif- ferent depending on the strain, which led to changes in the relative abundance of bacterial composition. Procedures such as soaking or smoking played an important role in shifting the microbial composition as well as changing biomarkers.

Amplicon-based microbiome sequencing using the $16 \mathrm{~S}$ rRNA gene is a powerful tool to assess and compare microbial community structure and diversity in a certain ecosystem. Although the $16 \mathrm{~S}$ rRNA gene amplicon sequencing is widely used to characterize the microbial taxonomic composition and phylogenetic diversity (Aßhauer et al., 2015), it is difficult to provide direct evidence of functional capabilities of microbiota (Iwai et al., 2016). The rapid growth in the number of sequenced genomes makes it possible to infer which functions are associated with a marker gene based on its sequence similarity when comparing it to a reference genome.

In the PFP of the cheese microbiome, the highest number of sequencing reads was assigned to carbohydrate metabolism and AA metabolism from both the PICRUSt2 and Piphillin analyses. It is not surprising that carbohydrate metabolism was the most abundant annotated functional property of the microbes present in cheese samples, as fermentation of carbohydrates is the key functional activity of cheese starter cultures. The primary carbohydrate metabolized by these or-

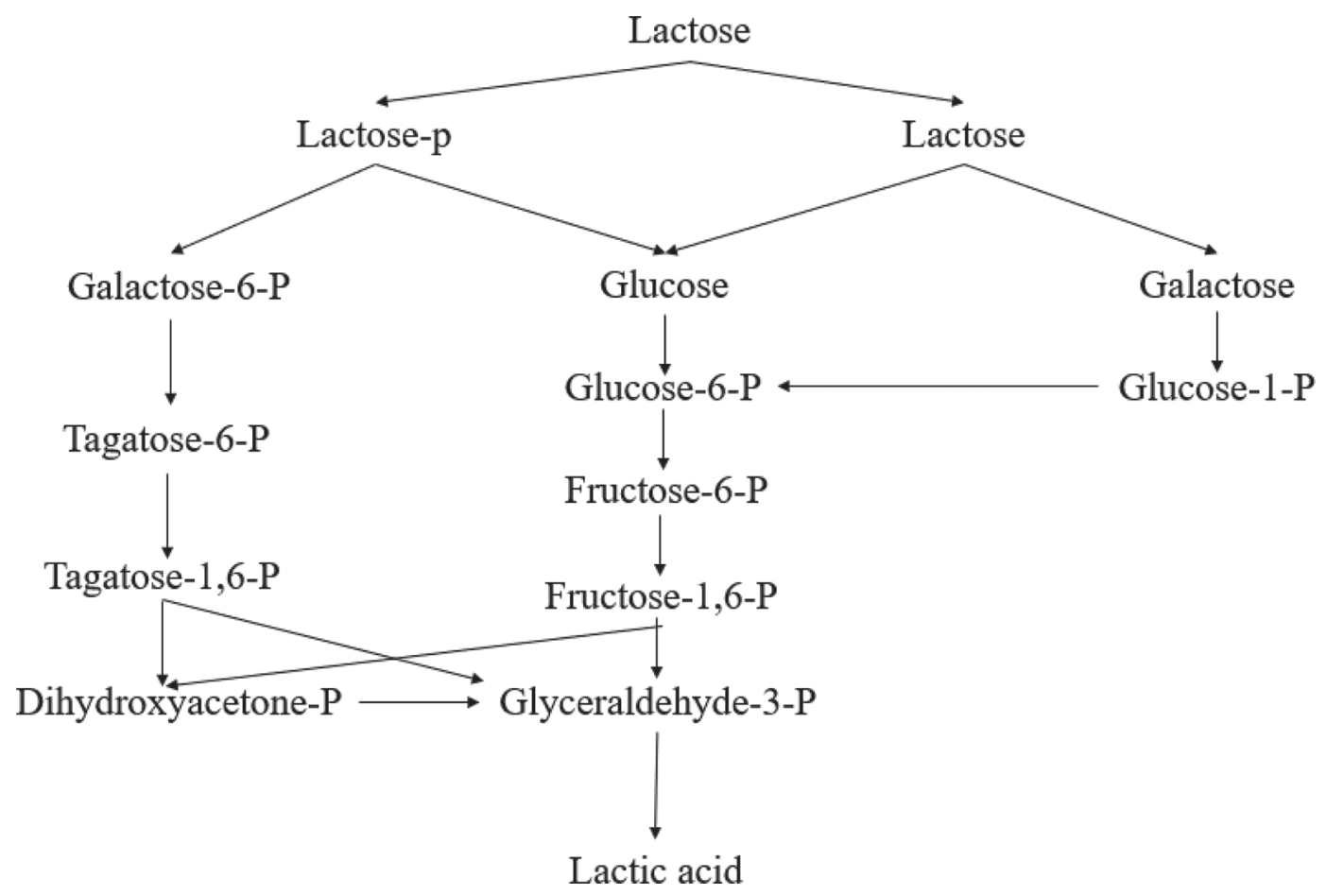

Figure 7. Lactic acid production pathway from cheese samples through lactic acid bacteria. 
ganisms is lactose, which is fermented into lactic acid and other metabolites (Porcellato and Skeie, 2016; Mataragas et al., 2018; Bautista-Gallego et al., 2019). Lactic acid fermentation in dairy products is a metabolic process that uses lactose to produce lactate in a lactic acid solution. It is an anaerobic fermentation reaction that occurs in a fermented food such as cheese and yogurt. Lactose [ $\beta$-D-galactopyranosyl- $(1 \rightarrow 4)$-Dglucose] is the primary sugar composed of glucose and galactose naturally found in milk and dairy products. Lactic acid bacteria metabolize lactose, glucose, and galactose to produce lactic acids through galactose and glycolysis/gluconeogenesis metabolisms (Figure 7). Among carbohydrate metabolites, functional genes related to lactic acid production accounted for more than $30 \%$ of the metabolomes. Another important role of the cheese microbiota is proteolysis and AA metabolism, which are important for texture and flavor development during cheese ripening (Ardö, 2006). In Figure 6, the differences in functional properties between different types of cheese were displayed in a PCA plot. Although the PCA plots from Piphillin and PICRUSt2 did not match exactly, both samples were clustered by the type of cheese. In a previous study, Wolfe et al. (2014) analyzed taxonomic diversity and functional properties of 137 different cheese rinds using a shotgun sequencing method. According to their metagenomic results, both taxonomic diversity and functional properties were related to each other and were strongly affected by the type of cheese. Functional potentials clustered by rind type, moisture content, and cheese making procedures (Wolfe et al., 2014; Dugat-Bony et al., 2016). Our findings correspond with previous reports that microbial diversity and functional property were significantly affected by the type of cheese.

\section{CONCLUSIONS}

The present study improves the understanding of composition, diversity, and functional properties of microbiota from different types of cheese through $16 \mathrm{~S}$ rRNA gene-based microbiome sequencing using the Illumina MiSeq platform. We compared the microbial community differences among 9 different types of cheese acquired from the Arbuthnot Dairy Center at Oregon State University (Corvallis, OR). In this study, we found that different types of cheese exhibited significant changes in microbial community structure, biomarkers, microbial diversity, and PFP, depending on the moisture content, rind formation, and color of rinds. This study provides better insight into the microbial properties of different cheese types, as well as locations within the cheese, to help manage the quality of cheese. In addition, future study is needed to investigate the 
potential influence of chemical compositional variations between the rind and the core regions of cheese on the microbiome.

\section{ACKNOWLEDGMENTS}

The authors thank Irene Hanning (University of Tennessee, Knoxville) and Daria Van de Grift, Ian A. Moppert, and Sushumna Canakapalli (Oregon State University, Corvallis) for their critical review. This research was partially supported by the Korean-American Scientists and Engineers Association (KSEA) Young Investigator Grants (YIG) and Oregon State University (Corvallis) start-up funds awarded to Si Hong Park, and Chung-Ang University Research Program (Anseong, Gyeonggi-Do, South Korea) awarded to Sang-Do Ha. The authors have stated no conflicts of interest.

\section{REFERENCES}

Ardö, Y. 2006. Flavour formation by amino acid catabolism. Biotechnol. Adv. 24:238-242. https://doi.org/10.1016/j.biotechadv.2005 .11 .005 .

Aßhauer, K. P., B. Wemheuer, R. Daniel, and P. Meinicke. 2015. Tax4Fun: Predicting functional profiles from metagenomic $16 \mathrm{~S} \mathrm{rRNA}$ data. Bioinformatics 31:2882-2884. https://doi.org/10.1093/ bioinformatics/btv287.

Bautista-Gallego, J., I. Ferrocino, C. Botta, D. Ercolini, L. Cocolin, and K. Rantsiou. 2019. Probiotic potential of a Lactobacillus rhamnosus cheese isolate and its effect on the fecal microbiota of healthy volunteers. Food Res. Int. 119:305-314. https://doi.org/10 .1016 /j.foodres.2019.02.004

Bokulich, N. A., and C. W. Bamforth, ed. 2017. Brewing Microbiology: Current Research, Omics and Microbial Ecology. Caister Academic Press, Wymondham, UK.

Bokulich, N. A., T. S. Collins, C. Masarweh, G. Allen, H. Heymann, S. E. Ebeler, and D. A. Mills. 2016. Associations among wine grape microbiome, metabolome, and fermentation behavior suggest microbial contribution to regional wine characteristics. MBio 7:e0631-16. https://doi.org/10.1128/mBio.00631-16.

Bokulich, N. A., and D. A. Mills. 2013. Facility-specific "house" microbiome drives microbial landscapes of artisan cheesemaking plants. Appl. Environ. Microbiol. 79:5214-5223. https://doi.org/10.1128/ AEM.00934-13.

Bolotin, A., P. Wincker, S. Mauger, O. Jaillon, K. Malarme, J. Weissenbach, S. D. Ehrlich, and A. Sorokin. 2001. The complete genome sequence of the lactic acid bacterium Lactococcus lactis ssp. lactis IL1403. Genome Res. 11:731-753. https://doi.org/10.1101/ gr.GR-1697R.

Bolyen, E., J. R. Rideout, M. R. Dillon, N. A. Bokulich, C. C. Abnet, G. A. Al-Ghalith, H. Alexander, E. J. Alm, M. Arumugam, F. Asnicar, Y. Bai, J. E. Bisanz, K. Bittinger, A. Brejnrod, C. J. Brislawn, C. T. Brown, B. J. Callahan, A. M. Caraballo-Rodríguez, J. Chase, E. K. Cope, R. Da Silva, C. Diener, P. C. Dorrestein, G. M. Douglas, D. M. Durall, C. Duvallet, C. F. Edwardson, M. Ernst, M. Estaki, J. Fouquier, J. M. Gauglitz, S. M. Gibbons, D. L. Gibson, A. Gonzalez, K. Gorlick, J. Guo, B. Hillmann, S. Holmes, H. Holste, C. Huttenhower, G. A. Huttley, S. Janssen, A. K. Jarmusch, L. Jiang, B. D. Kaehler, K. B. Kang, C. R. Keefe, P. Keim, S. T. Kelley, D. Knights, I. Koester, T. Kosciolek, J. Kreps, M. G. I. Langille, J. Lee, R. Ley, Y. X. Liu, E. Loftfield, C. Lozupone, M. Maher, C. Marotz, B. D. Martin, D. McDonald, L. J. McIver, A. V. Melnik, J. L. Metcalf, S. C. Morgan, J. T. Morton, A. T. Naimey, J. A. Navas-Molina, L. F. Nothias, S. B. Orchanian,
T. Pearson, S. L. Peoples, D. Petras, M. L. Preuss, E. Pruesse, L. B. Rasmussen, A. Rivers, M. S. Robeson, P. Rosenthal, N. Segata, M. Shaffer, A. Shiffer, R. Sinha, S. J. Song, J. R. Spear, A. D. Swafford, L. R. Thompson, P. J. Torres, P. Trinh, A. Tripathi, P. J. Turnbaugh, S. Ul-Hasan, J. J. J. van der Hooft, F. Vargas, Y. Vázquez-Baeza, E. Vogtmann, M. von Hippel, W. Walters, Y. Wan, M. Wang, J. Warren, K. C. Weber, C. H. D. Williamson, A. D. Willis, Z. Z. Xu, J. R. Zaneveld, Y. Zhang, Q. Zhu, R. Knight, and J. G. Caporaso. 2019. Reproducible, interactive, scalable and extensible microbiome data science using QIIME 2. Nat. Biotechnol. 37:852-857.

Broadbent, J. R., H. Cai, R. Larsen, J. Hughes, D. Welker, V. de Carvalho, T. Tompkins, Y. Ardö, F. Vogensen, A. de Lorentiis, M. Gatti, E. Neviani, and J. L. Steele. 2011. Genetic diversity in proteolytic enzymes and amino acid metabolism among Lactobacillus helveticus strains. J. Dairy Sci. 94:4313-4328. https://doi.org/10 .3168/jds.2010-4068.

Cousin, F. J., R. Le Guellec, M. Schlusselhuber, M. Dalmasso, J. M. Laplace, and M. Cretenet. 2017. Microorganisms in fermented apple beverages: Current knowledge and future directions. Microorganisms 5:E39. https://doi.org/10.3390/microorganisms5030039.

De Filippis, F., A. Genovese, P. Ferranti, J. A. Gilbert, and D. Ercolini. 2016. Metatranscriptomics reveals temperature-driven functional changes in microbiome impacting cheese maturation rate. Sci. Rep. 6:21871. https://doi.org/10.1038/srep21871.

De Filippis, F., A. La Storia, G. Stellato, M. Gatti, and D. Ercolini. 2014. A selected core microbiome drives the early stages of three popular Italian cheese manufactures. PLoS One 9:e89680.

Dhariwal, A., J. Chong, S. Habib, I. L. King, L. B. Agellon, and J. Xia. 2017. MicrobiomeAnalyst: A web-based tool for comprehensive statistical, visual and meta-analysis of microbiome data. Nucleic Acids Res. 45(W1):W180-W188. https://doi.org/10.1093/ nar/gkx295.

Didienne, R., C. Defargues, C. Callon, T. Meylheuc, S. Hulin, and M. C. Montel. 2012. Characteristics of microbial biofilm on wooden vats ('gerles') in PDO Salers cheese. Int. J. Food Microbiol 156:91-101. https://doi.org/10.1016/j.ijfoodmicro.2012.03.007.

Donnelly, C. W. 2014. Cheese and Microbes. ASM Press, Washington, DC.

Douglas, G. M., R. G. Beiko, and M. G. Langille. 2018. Predicting the functional potential of the microbiome from marker genes using PICRUSt. Methods Mol. Biol. 1849:169-177. https://doi.org/10 .1007/978-1-4939-8728-3_11.

Dugat-Bony, E., L. Garnier, J. Denonfoux, S. Ferreira, A. S. Sarthou, P. Bonnarme, and F. Irlinger. 2016. Highlighting the microbial diversity of 12 French cheese varieties. Int. J. Food Microbiol. 238:265-273. https://doi.org/10.1016/j.ijfoodmicro.2016.09.026.

Duru, I. C., P. Laine, M. Andreevskaya, L. Paulin, S. Kananen, S. Tynkkynen, P. Auvinen, and O. P. Smolander. 2018. Metagenomic and metatranscriptomic analysis of the microbial community in Swiss-type Maasdam cheese during ripening. Int. J. Food Microbiol. 281:10-22. https://doi.org/10.1016/j.ijfoodmicro.2018.05.017.

Felis, G. E., and B. Pot. 2014. The family of Lactobacilliceae. Pages 245-247 in Lactic Acid Bacteria: Biodiversity and Taxonomy. W. H. Holzapfel and J. B. Wood, ed. Wiley, Hoboken, NJ.

Gobbetti, M., M. de Angelis, R. di Cagno, L. Mancini, and P. F. Fox. 2015. Pros and cons for using non-starter lactic acid bacteria (NSLAB) as secondary/adjunct starters for cheese ripening. Trends Food Sci. Technol. 45:167-178. https://doi.org/10.1016/j .tifs.2015.07.016.

Iwai, S., T. Weinmaier, B. L. Schmidt, D. G. Albertson, N. J. Poloso, K. Dabbagh, and T. Z. de Santis. 2016. Piphillin: Improved prediction of metagenomic content by direct inference from human microbiomes. PLoS One 11:e0166104. https://doi.org/10.1371/ journal.pone.0166104.

Kozich, J. J., S. L. Westcott, N. T. Baxter, S. K. Highlander, and P. D. Schloss. 2013. Development of a dual-index sequencing strategy and curation pipeline for analyzing amplicon sequence data on the MiSeq Illumina sequencing platform. Appl. Environ. Microbiol. 79:5112-5120. https://doi.org/10.1128/AEM.01043-13. 
Langille, M. G., J. Zaneveld, J. G. Caporaso, D. McDonald, D. Knights, J. A. Reyes, J. C. Clemente, D. E. Burkepile, R. L. V. Thurber, and R. Knight. 2013. Predictive functional profiling of microbial communities using 16S rRNA marker gene sequences. Nat. Biotechnol. 31:814-821. https://doi.org/10.1038/nbt.2676.

Majcher, M. A., K. Goderska, J. Pikul, and H. H. Jeleń. 2011. Changes in volatile, sensory and microbial profiles during preparation of smoked ewe cheese. J. Sci. Food Agric. 91:1416-1423. https://doi .org/10.1002/jsfa.4326.

Mataragas, M., V. Alessandria, I. Ferrocino, K. Rantsiou, and L. Cocolin. 2018. A bioinformatics pipeline integrating predictive metagenomics profiling for the analysis of $16 \mathrm{~S}$ rDNA/rRNA sequencing data originated from foods. Food Microbiol. 76:279-286. https://doi.org/10.1016/j.fm.2018.05.009.

Mayo, B., T. C. C. Rachid, A. Alegria, A. Leite, R. Peixoto, and S. Delgado. 2014. Impact of next generation sequencing techniques in food microbiology. Curr. Genomics 15:293-309. https://doi.org/10 2174/1389202915666140616233211.

McDonald, D., M. N. Price, J. Goodrich, E. P. Nawrocki, T. Z. de Santis, A. Probst, G. L. Andersen, R. Knight, and P. Hugenholtz. 2012. An improved Greengenes taxonomy with explicit ranks for ecological and evolutionary analyses of bacteria and archaea. ISME J. 6:610-618. https://doi.org/10.1038/ismej.2011.139.

Montel, M. C., S. Buchin, A. Mallet, C. Delbes-Paus, D. A. Vuitton, N. Desmasures, and F. Berthier. 2014. Traditional cheeses: Rich and diverse microbiota with associated benefits. Int. J. Food Microbiol. 177:136-154. https://doi.org/10.1016/j.ijfoodmicro.2014 .02 .019 .

Mora, D., M. Fortina, C. Parini, G. Ricci, M. Gatti, G. Giraffa, and P. Manachini. 2002. Genetic diversity and technological properties of Streptococcus thermophilus strains isolated from dairy products. J. Appl. Microbiol. 93:278-287. https://doi.org/10.1046/j.1365-2672 .2002.01696.x.

Parks, D. H., G. W. Tyson, P. Hugenholtz, and R. G. Beiko. 2014. STAMP: Statistical analysis of taxonomic and functional profiles. Bioinformatics 30:3123-3124. https://doi.org/10.1093/ bioinformatics/btu494.

Percival, B., and F. Percival. 2017. Reinventing the Wheel: Milk, Microbes, and the Fight for Real Cheese. Vol. 65. University of California Press, Oakland.

Pintado, M., and F. X. Malcata. 2000. Characterization of whey cheese packaged under vacuum. J. Food Prot. 63:216-221. https://doi .org/10.4315/0362-028X-63.2.216.

Porcellato, D., and S. B. Skeie. 2016. Bacterial dynamics and functional analysis of microbial metagenomes during ripening of Dutch- type cheese. Int. Dairy J. 61:182-188. https://doi.org/10.1016/j .idairyj.2016.05.005.

Potočki, S. 2016. Potential health benefits of sphingolipids in milk and dairy products. Mljekarstvo 66:251-261. https://doi.org/10.15567/ mljekarstvo.2016.0401.

Schleifer, K., J. Kraus, C. Dvorak, R. Kilpper-Bälz, M. Collins, and W. Fischer. 1985. Transfer of Streptococcus lactis and related streptococci to the genus Lactococcus gen. nov. Syst. Appl. Microbiol. 6:183-195. https://doi.org/10.1016/S0723-2020(85)80052-7.

Schmitz-Esser, S., M. Dzieciol, E. Nischler, E. Schornsteiner, O. Bereuter, E. Mann, and M. Wagner. 2018. Abundance and potential contribution of Gram-negative cheese rind bacteria from Austrian artisanal hard cheeses. Int. J. Food Microbiol. 266:95-103. https://doi.org/10.1016/j.ijfoodmicro.2017.11.013.

Segata, N., J. Izard, L. Waldron, D. Gevers, L. Miropolsky, W. S. Garrett, and C. Huttenhower. 2011. Metagenomic biomarker discovery and explanation. Genome Biol. 12:R60. https://doi.org/10.1186/ gb-2011-12-6-r60.

Solieri, L., T. C. Dakal, and P. Giudici. 2013. Next-generation sequencing and its potential impact on food microbial genomics. Ann. Microbiol. 63:21-37. https://doi.org/10.1007/s13213-012-0478-8.

Takano, T. 2002. Anti-hypertensive activity of fermented dairy products containing biogenic peptides. Antonie Van Leeuwenhoek 82:333-340. https://doi.org/10.1023/A:1020600119907.

Walther, B., A. Schmid, R. Sieber, and K. Wehrmüller. 2008. Cheese in nutrition and health. Dairy Sci. Technol. 88:389-405. https:// doi.org/10.1051/dst:2008012.

Wolfe, B. E., J. E. Button, M. Santarelli, and R. J. Dutton. 2014. Cheese rind communities provide tractable systems for in situ and in vitro studies of microbial diversity. Cell 158:422-433. https:// doi.org/10.1016/j.cell.2014.05.041.

Yeluri Jonnala, B. R., P. L. McSweeney, J. J. Sheehan, and P. D. Cotter. 2018. Sequencing of the cheese microbiome and its relevance to industry. Front. Microbiol. 9:1020.

\section{ORCIDS}

Sang In Lee 니 https://orcid.org/0000-0002-8946-4471 Lisbeth Goddik @ https://orcid.org/0000-0002-3657-7173

Robin Frojen ๑ https://orcid.org/0000-0003-4549-6663

Jang H. Kim ๑ https://orcid.org/0000-0001-8124-2340

Si Hong Park @ (ㄴ) https://orcid.org/0000-0001-6587-7020 